\title{
Long overdue improvement of box corer sampling
}

\author{
Sven Blomqvist ${ }^{1, *}$, Nils Ekeroth ${ }^{1}$, Ragnar Elmgren ${ }^{1}$, Per O. J. Hall ${ }^{2}$ \\ ${ }^{1}$ Department of Ecology, Environment and Plant Sciences, Stockholm University, 10609 Stockholm, Sweden \\ ${ }^{2}$ Department of Marine Sciences, University of Gothenburg, 41296 Gothenburg, Sweden
}

\begin{abstract}
An improved, large double-jawed box corer, intended primarily for sampling of soft sediments on continental margins and in large lakes, is described. The device performs reliably when entering the sediment and enclosing the sample, during withdrawal and hoisting on board the ship and also when detaching the collected sediment sample. It offers the following advantages: (1) robust design, (2) minimally impeded flow of water through the box chamber during lowering and (3) an efficient closure mechanism. It is furnished with a supporting stand, a transparent liner and an accessory anti-slosh baffle for insertion in the liner as the corer is set down on the ship's deck. In situ video records and turbidity measurements from field trials, as well as visual inspection of the core and supernatant water after retrieval, show that the device collects minimally disturbed sediment when properly and carefully operated. This contrasts with the bulky United States Naval Electronics Laboratory (USNEL) Spade Corer in which water flow through the box chamber during lowering is impeded, causing a bow-wave ahead of the corer that displaces surficial sediment. In addition, the USNEL's single-spade closing mechanism deforms the sediment sample severely and can even cause loss of sediment. Our new box corer performs much better, making it suitable for quantitative benthic sampling.
\end{abstract}

KEY WORDS: Box corer - Spade corer - United States Naval Electronics Laboratory - USNEL · Soft sediment sampling $\cdot$ Benthos $\cdot$ Continental margin

\section{INTRODUCTION}

Considering the critical need for representative sediment samples from the continental margin, detailed examinations of the performance of sampling devices commonly used on such sediments are surprisingly scarce, particularly for large box corers.

A properly designed and operated box corer (Blomqvist 1990, 1991) is suitable for collecting zoobenthos (Gage \& Tyler 1991, Paterson et al. 1998), surficial sediments (McCave 1985, Ekeroth et al. 2012) and surface concretions (Hessler \& Jumars 1974, Veillette et al. 2007). A box corer can also be used for sub-coring to minimize core shortening or for taking replicate subsamples (Blomqvist \& Boström 1987). In sheltered coastal areas and shallow lakes,

\footnotetext{
*Corresponding author: sven.blomqvist@su.se
}

small gravity corers that collect the sample in a box or open-ended barrel can be adequate (e.g. Blomqvist \& Abrahamsson 1985, Blomqvist 1990). However, in open sea areas, large open-barrel corers (Barnett et al. 1984, Papucci et al. 1986, Gerber et al. 1996) or large box corers (Jonasson \& Olausson 1966, Hessler \& Jumars 1974, Boland \& Rowe 1991) are often preferred because they provide larger samples.

Here, we describe an improved large box corer, intended primarily for sampling of soft sediments on continental margins and in large lakes. It is robust and operates according to earlier developed criteria (Blomqvist 1991). Practical experience from field trials, in situ video recordings and turbidity measurements from the box chamber demonstrate that it performs reliably.

() The authors 2015. Open Access under Creative Commons by Attribution Licence. Use, distribution and reproduction are unrestricted. Authors and original publication must be credited. 


\section{History in brief}

The invention of the box corer dates back to the small Ekman (1911) grab, which was intended primarily for use in lakes. Later, larger Ekman grabs were developed for marine conditions (Ekman 1933, Rawson 1947). Today, most large box corers are based on principles proposed about half a century ago (Reineck 1958, 1963, Bouma \& Marshall 1964, Rosfelder \& Marshall 1967). Elmgren (1973) already stressed the need for testing the sampling efficiency of such corers.

Several types of large box corers have been developed (e.g. Peters et al. 1980, Gerdes 1990, Boland \& Rowe 1991). Though widely used, the reliability and limitations of such large box corers have really never been critically examined in situ. Earlier intercomparisons (Smith \& Howard 1972, Elmgren 1973, Beukema 1974, Probert 1984, Boland \& Rowe 1991, Hayashi \& Sugino 1993, Bett et al. 1994, Shirayama \& Fukushima 1995, Somerfield \& Clarke 1997, Gage \& Bett 2005) only compared the performance of different bottom samplers, but failed to provide firm evidence that any of them provides reliable and representative sediment samples. Thus, sampling of offshore sediments has long been based more on faith than science.

\section{Scope}

Here, we describe a new, large box corer, developed from that originally invented by Jonasson \& Olausson (1966). Elmgren (1973) reported that sampled sediment was resuspended in the box chamber of the Jonasson-Olausson corer, leading to deficient collection of meiofauna. Loss of soft sediments including meiofauna is a common problem when the seafloor is remotely sampled (McIntyre 1971, Jensen 1983, Bett et al. 1994).

Compared with the previous design, the new box corer (Fig. 1) has improved basic construction and mechanical functioning, and some useful new accessories. We compare its sampling performance with that of the marine box corer used most frequently over the last half-century. Our article only compares sampling devices with the same mode of sediment collection, and other sampling devices, e.g. leaf bags, can add valuable information by sampling a partly different animal assemblage (e.g. Sangiorgio et al. 2014).

\section{MATERIALS AND METHODS}

We evaluated the new box corer with videorecordings and measurements of turbidity in the

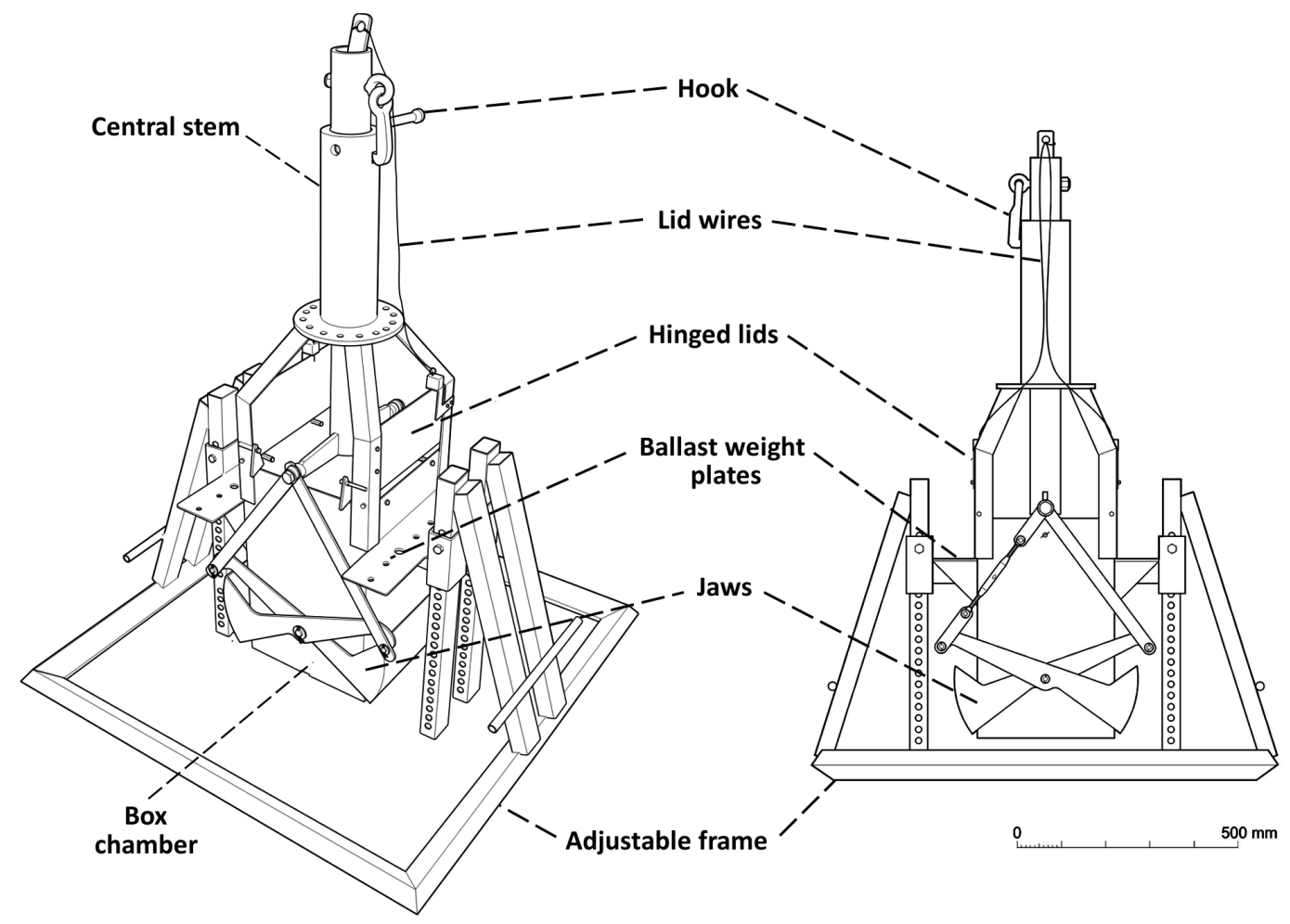

Fig. 1. Improved, large double-jawed box corer in cocked state 
supernatant water during field sampling, as well as by visual inspection of the sediment samples on the deck of the ship after retrieval.

\section{Studied corer}

Like the original large box corer, the 'Kastengreifer' of Reineck (1958, 1963), our new device consists of a sampling box chamber attached to a central stem (Fig. 1). The container box measures $280 \times$ $280 \mathrm{~mm}$ inside and is $500 \mathrm{~mm}$ in height. A supporting stand (hollow frame $1.04 \times 1.04 \mathrm{~m}$ ) facilitates the adjustment of the sediment penetration depth, and counteracts tilting of the box corer. Penetration depth can be increased by attaching lead ballast weights to the horizontal plates (Fig. 1). In cocked state, the device is $1.40 \mathrm{~m}$ high. The corer is made of high quality, argon-welded acid-proof stainless steel (EN 1.4404), and is therefore rather heavy (110 kg in air).

\section{Operation}

The sampler is in cocked position during lowering, with the upper hinged lids (shutters) and the lower jaws kept fully open (Fig. 1). The minimally restricted water flow through the box chamber minimizes formation of a bow-wave. As the corer enters the sediment, the attachment wire slackens, releasing the tipping hook. This hook is furnished with a casted peg to keep the hook away from the groove during lifting. On withdrawal, the box corer is closed by 2 pivoting jaws. The box chamber has mechanisms that keep the shutters fully open during lowering, and locked closed during retrieval (Fig. 1).

When the box corer is retrieved and carefully opened on deck, an inside liner of $8 \mathrm{~mm}$ thick, transparent polycarbonate allows ready subsampling of the collected sediment. The liner box with the sediment is easily removed from the box corer, permitting visual inspection of the sediment and making the sample freely accessible from above, allowing, for example, sub-coring (Blomqvist \& Boström 1987) followed by vertical or horizontal sectioning (e.g. Ambühl 1985, Blomqvist \& Abrahamsson 1987, Kornijów 2013). The detached liner can also be used as an aquarium (box-cosm) for experimental studies.

Before the liner is detached from the corer, an accessory baffle (Fig. 2) can be inserted to reduce sloshing of supernatant water and sediment resuspension during handling and transport.
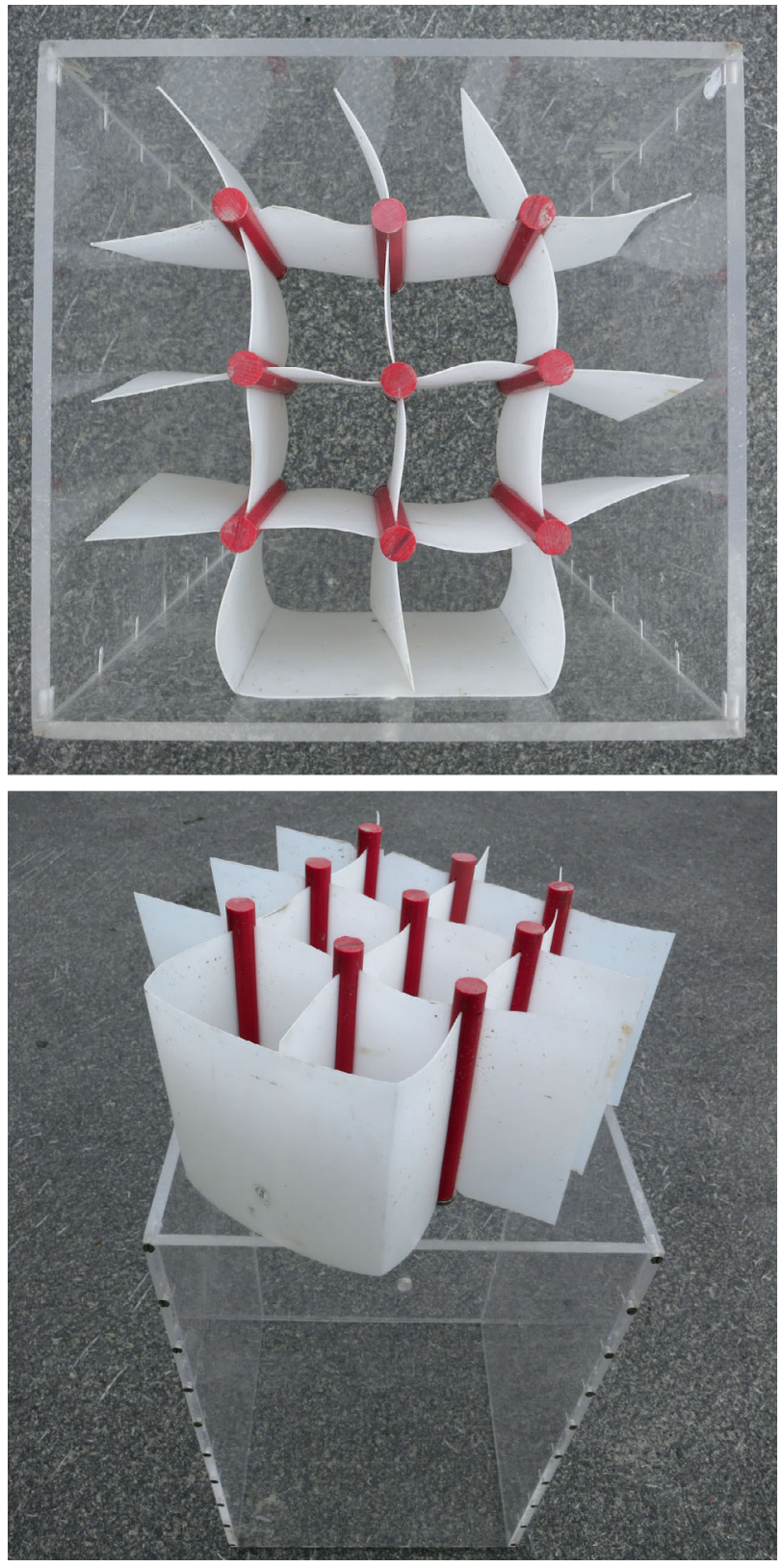

Fig. 2. Accessory anti-slosh baffle for the box corer liner

\section{Documentation}

The operation of the box corer was documented in situ by a video recorder (GoPro Hero 3 Silver edition, see Supplementary videos 1-4 at www.int-res.com/ articles/suppl/m538p013_supp/) fixed to the device. A dive video light source (F.I.T. LED 2400 WSR of $7400 \mathrm{~K}$ and 1100 lumen) was mounted on the device. The high-resolution video recording allowed critical evaluation of the sampling procedure by repeated slow-motion visual inspection. 
Turbidity was recorded in situ after core penetration into the sediment, both just outside and inside the box chamber using turbidity sensors (model 3612A, Aanderaa Data Instruments). The measuring range was 0-100 normal turbidity units (NTU), with a resolution of $0.1 \%$ and accuracy $\pm 1 \%$. The sensor inside the box chamber recorded turbidity ca. $5 \mathrm{~cm}$ above the sampled sediment surface. The outside sensor was mounted on the box chamber, close to the shutters. Data were logged every $14 \mathrm{~s}$ by an Aanderaa RCM9 data logger mounted on the box corer.

\section{Field trials}

We conducted field trials on soft sediments in the open Baltic proper (north-west of the island of Gotland, Sweden, at $150 \mathrm{~m}$ depth), in archipelago areas of the Baltic proper (Tvären at $50 \mathrm{~m}$, harbours of Askö at $8 \mathrm{~m}$ and Muskö $3 \mathrm{~m}$ ), in the Bothnian Sea (Sundsvall Bight at $11 \mathrm{~m}$ depth) and in Skagerrak fjords (Byfjorden, 7-35 m depth, and Koljöfjorden, 15-22 m). The box corer was lowered rapidly through the water column. The speed of the corer when entering the sediment was deliberately varied in order to study the effect on sampling performance. The initial withdrawal from the sediment was slow and careful, followed by a rapid retrieval. When nearing the ship, the winching speed was again reduced, and the corer gently hoisted on board.

\section{RESULTS AND DISCUSSION}

Our field trials demonstrated that the box corer works reliably when properly operated. This applies to penetration into the sediment, enclosing of the sediment sample, withdrawal and hoisting the device on board the ship and detachment of the sample liner containing the sediment core.

\section{Lowering and sediment penetration}

The weight of the box corer kept the attachment wire tight, preventing accidental release of the device during lowering. When the box corer entered the sediment slowly $\left(<2 \mathrm{~m} \mathrm{~min}^{-1}\right)$, video recordings showed some resuspension into the supernatant water when the sediment surface was fluffy, but little when the sediment was stabilized by a cohesive surface gel layer (Supplementary video 1).

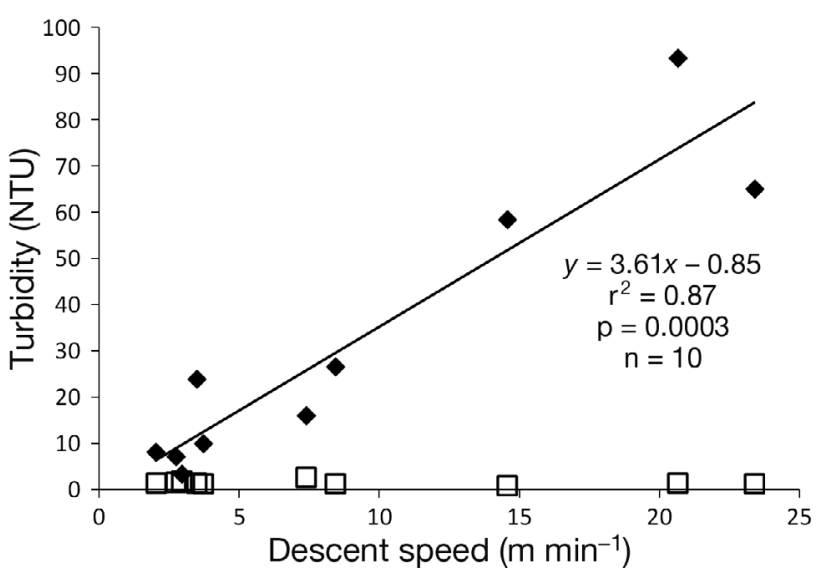

Fig. 3. Maximum turbidity inside the box chamber versus the corer's lowering speed when entering the sediment (filled diamonds and linear regression line). Open squares show background turbidity of the ambient bottom water

When lowered at $2 \mathrm{~m} \mathrm{~min}^{-1}$ into a sediment without a cohesive surface gel layer, in Askö harbour, turbidity increased 3-fold (Fig. 3) from a low background level (1.4-2.9 NTU). As the lowering speed of the corer was increased in steps to ca. $24 \mathrm{~m} \mathrm{~min}^{-1}$, turbidity increased strongly and linearly up to $90 \mathrm{NTU}$, or 60 times the background level (Fig. 3).

Regardless of lowering speed, resuspension was common if the box corer moved sideways as it entered the sediment (Supplementary video 2). Such horizontal movement of the box corer also led to the formation of a gap between the liner wall and the enclosed sediment (Fig. 4, Supplementary video 3). Gap formation is an insidious phenomenon that may result in some burial of surficial sediment and organisms, and exposure of underlying deeper sediment strata to the overlying water phase. Such gap formation has previously been reported from in situ observations of an Ekman grab (Blomqvist 1985).

Initially resuspended sediment had often settled again by the time the sample was examined on board the ship. When the box corer was left resting on the sediment in cocked position with the shutters open after a resuspension event, the turbidity of the water within the box chamber water decreased rapidly, and was back to background levels within $1 \mathrm{~min}$ (Fig. 5). Hence, clear supernatant water after retrieval (e.g. Soutar et al. 1981) does not guarantee that the sample was undisturbed during sampling, and some means to detect resuspension in situ should thus be used when this kind of bias is suspected. 


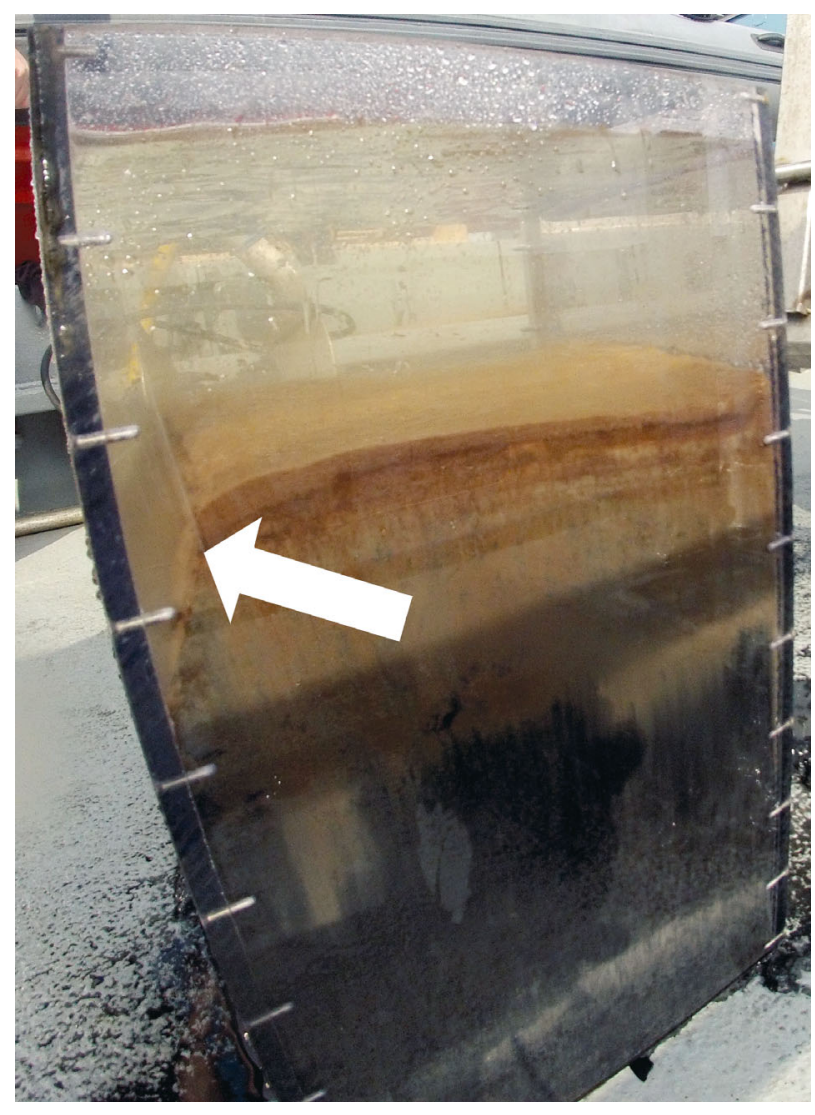

Fig. 4. Sediment box core from the Sundsvall Bight. Arrow indicates wedge-shaped gap due to sideways movement of the box corer during sediment penetration

\section{Supporting stand}

In addition to bow-wave impact and sideways drift, resuspension and redistribution of sediment in a box corer can also result from tilting or overfilling of the sampler before withdrawal from the sediment (Blomqvist 1990). Our corer's frame minimizes such disturbances, and we observed no such bias in our trials.

Our videos of the sampling procedure demonstrate that the supporting stand maintains the box corer in vertical position when resting on the bottom. It also allows height adjustment of the corer to obtain a desired sediment penetration depth. During sampling, the frame should be positioned so that the orifice of the chamber box is below the frame. In this way, sediment resuspended by the frame was never observed to reach the cored area before the box chamber had entered the sediment surface, and closed it off.

Previously, a variety of supporting stands (feet, legs and frames) have been mounted on box corers (Rawson 1947, Peters et al. 1980, Blomqvist 1990, Gerdes 1990, Gerber et al. 1996, Lund-Hansen et al. 2001, Black et al. 2002). In addition to providing vertical stability during sampling, such stands protect the coring unit during transport and use. If needed, our frame is easily dismantled to make the new box corer less bulky during transport and storage.
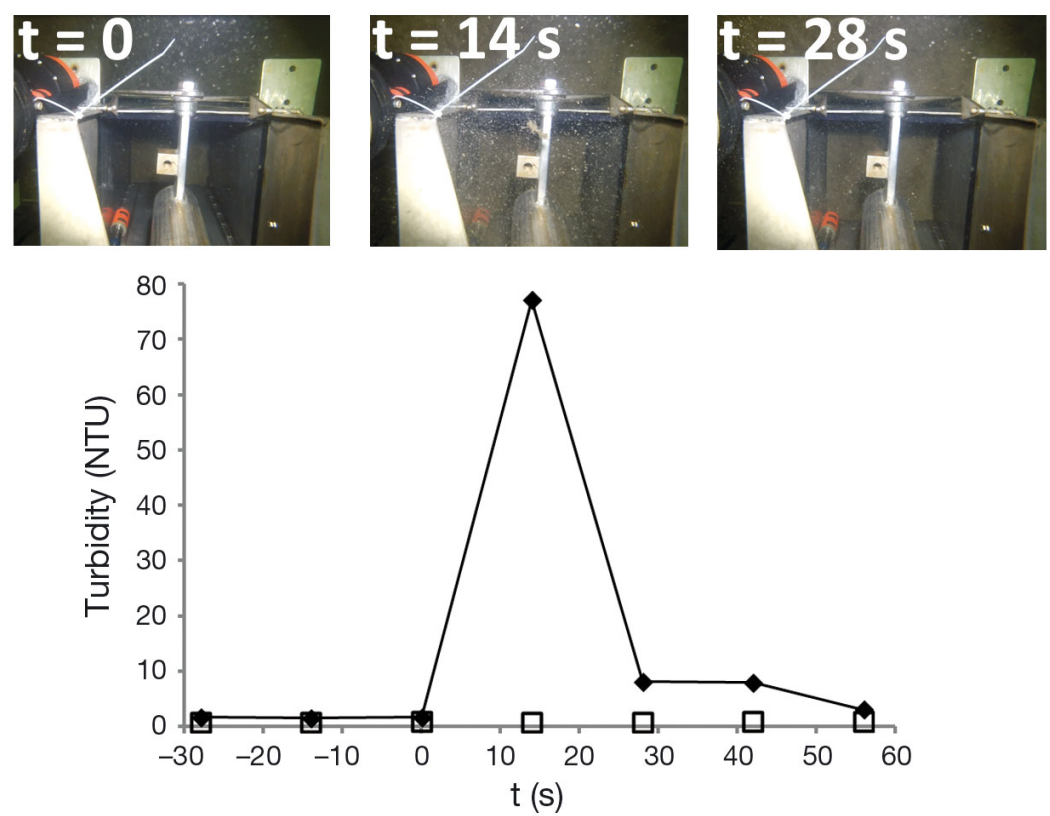

Fig. 5. Turbidity recorded inside (filled diamonds) and outside (open squares) the box chamber during sediment collection near Askö. Time given (seconds) relative to the moment of sediment contact $(t=0)$

\section{Retrieval}

Late closing of the box corer jaws can easily cause sediment loss (Blomqvist 1990). However, the pivoting jaws of our device prevent this, since the jaws are strongly forced shut by the lever arms (Fig. 1) before the corer begins to rise. This ensures that a complete sediment column is acquired. In stiff sediment, the closing of the jaws can be delayed, but such malfunction can be counteracted by loading the device with extra weights. We observed delayed closing only in stiff sandy sediment from the Sundsvall Bight.

In contrast to many small box corers, the new heavy box corer did not revolve during retrieval, and therefore did not subject the surface sediment to entrainment by shear stress by the supernatant water (Blomqvist 1990). 
Hence, we saw no evidence of resuspension at this stage of sampling.

\section{Shortcomings of a commonly used large box corer}

We compared the performance of our new box corer with that of the even larger $(760 \mathrm{~kg})$ United States Naval Electronics Laboratory (USNEL) Spade Corer (Hessler \& Jumars 1974), until now the 'work horse' of many open-ocean benthic studies (e.g. Gage \& Tyler 1991, Paterson et al. 1998, Billett \& Rice 2001, Zettler \& Pollehne 2013).

The USNEL Spade Corer is bulky, which increases bow-wave formation. This is intensified by the severely impeded water flow through the narrow vents at the top of the corer chamber (Fig. 6). Thus, the USNEL and similar box corers have a strong propensity for disturbing the sediment during sampling, especially at the recommended, very high lowering speeds $\left(15-25 \mathrm{~m} \mathrm{~min}^{-1}\right.$ or $10-30 \mathrm{~m} \mathrm{~min}^{-1}$ for the USNEL, Gage \& Tyler 1991, Jamieson et al. 2013). Indeed, during our trials, the supernatant water over the sampled sediment was highly turbid when inspected on deck.

Sediment displacement by the bow-wave and loss of material through the vents may explain the systematic underestimates of metazoan abundance reported from the northeast Atlantic (Bett et al. 1994), and for harpacticoids in Suruga Bay, east Japan (Shirayama \& Fukushima 1995).

The central stem of the USNEL corer rotates around the gimbal axis when the spade closes (Supplementary video 4 ). The resulting lateral displacement of the box chamber might result in formation of a wedge-shaped gap between the enclosed sediment and the inclined wall (cf. Blomqvist 1985), with accompanying resuspension and redistribution in the box chamber. Also, this gap might even result in loss of enclosed matter through the bottom of the device if the gap extends all the way down to the edge of the box chamber orifice. Such gap formation in the sediment sample is a treacherous biasing factor, and is difficult to recognize unless visually documented inside the chamber, or through a transparent box corer liner.

In the USNEL corer, tilting is probably an inevitable result of unilateral forcing by the singlespade construction on closing. Therefore, some bias must be expected in all similar single-spade corers, although the extent of tilting may vary with the weight and other technical aspects of the design. The physical properties of the sediment (e.g. stiffness)

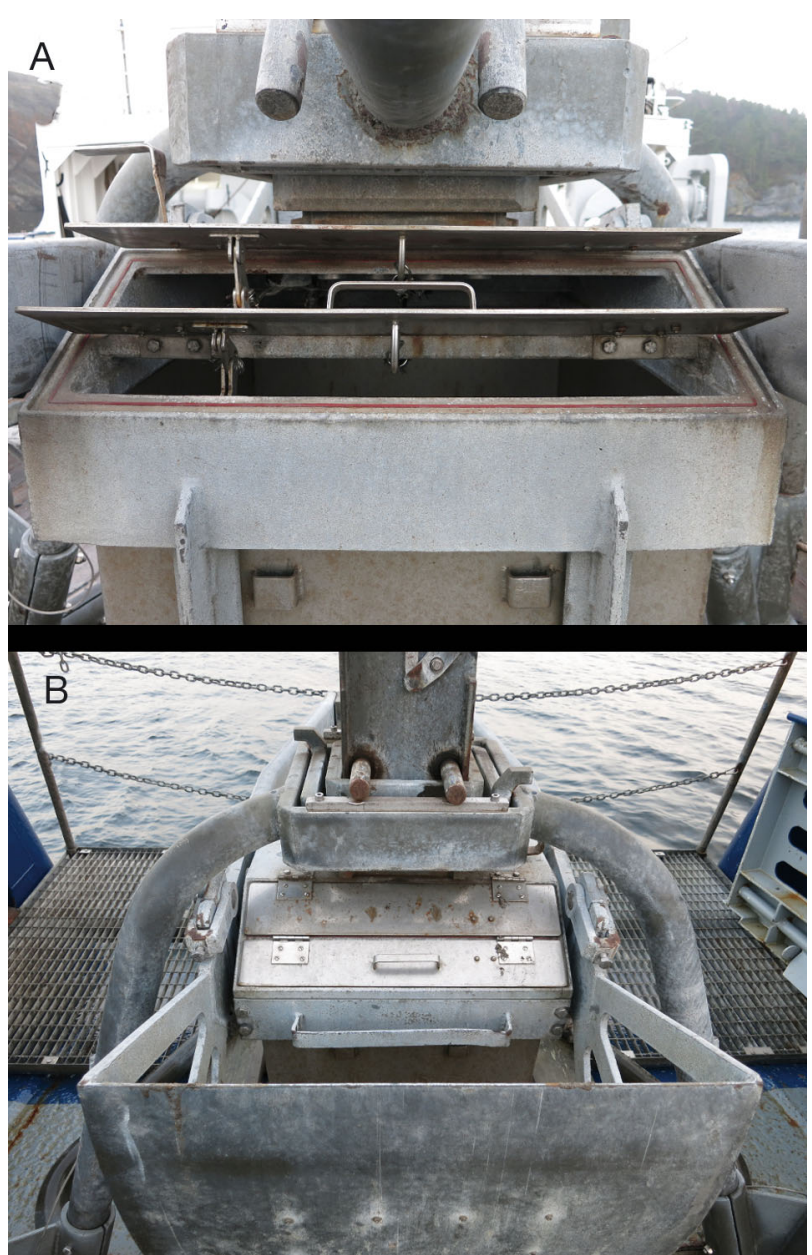

Fig. 6. United States Naval Electronics Laboratory (USNEL) box corer. Flapper vents in (A) open and (B) shut position

will also affect the extent of sampling bias, as reported for grabs (Blomqvist 1991).

Our comparison calls into question the reliability of most purportedly quantitative box core samples of soft sediments in coastal seas, large lakes and the open ocean, during the last century. The USNEL box corer has often been considered a reliable standard sampler (e.g. Smith \& Howard 1972, Beukema 1974, Hayashi \& Sugino 1993), but our field studies indicate that this is overly optimistic.

\section{REMARKS}

Continental margins occupy one-fifth of the world ocean (Walsh 1984) and are estimated to store most of the organic carbon buried in the marine environment (Hedges \& Keil 1995, Burdige 2007). This burial is linked to the marine cycling of nitrogen (Gruber 
2008), phosphorus (Howarth et al. 1995, Föllmi 1996, Ruttenberg 2004) and silica (DeMaster 2002, Laruelle et al. 2009). Hence, in order to understand, quantify and monitor the ecological, geochemical and environmental dynamics of continental margin bottom sediments, reliable sampling is a prerequisite.

Properly designed and operated, large box corers can be reliable devices for sampling of soft bottom sediments. However, the severe systematic sampling bias demonstrated for the USNEL Spade Corer is remarkable. It calls for caution when evaluating data obtained with this and similar box corers that have a single-spade closure mechanism or form bow-waves causing downwash displacement of surficial sediment in front of the device.

The new, improved sediment sampler described here appears to be one of the most reliable large box corers available. Our tests (Fig. 3, Supplementary video 1), demonstrate that it provides highly representative bottom samples. Its low propensity for sample resuspension is due to a combination of slow lowering, minimally impeded flow of water through the box chamber, vertical stability when resting on the seafloor, and a reliable enclosing of the sediment sample.

The use of an accessory baffle can help reduce resuspension. Nevertheless, successful sampling of sediments, particularly those with an easily disturbed, fluffy surface, requires low sea state, accurate positioning and a stable ship. This permits the slow and completely vertical approach and entering of the sampler into the bottom sediment, without which the samples can be disturbed and misleading. However, in open seas, such conditions are the exception rather than the rule.

Considering the critical need for truly representative quantitative samples, it is strongly recommended (cf. Blomqvist 1991) that the corer device is equipped with a visual recorder (photographic or video, cf. Peters et al. 1980, Gerdes 1990, LundHansen et al. 2001, Black et al. 2002) and a transparent liner (cf. Karl 1976, Papucci et al. 1986) to allow checks of the quality of samples obtained. Our study demonstrates that turbidity measurements can be used to detect resuspension (Figs. 3 \& 5) and define optimal corer lowering speeds.

Lack of such information from past box corer sampling casts a shadow of doubt over historical sediment data. If improved box corers are used in the future, this uncertainty can be largely eliminated, but only during favourable conditions. For use during less favourable sea states, a hydraulically damped, autonomously operating technique, similar to that of certain corers (Craib 1965, Pamatmat 1971, Peters et al. 1980, Barnett et al. 1984, Jahnke \& Knight 1997, Lund-Hansen et al. 2001), would be a further improvement.

Acknowledgements. Fig. 1 was drawn by the late Leif Lundgren, a true friend, reliable sea hand and skilful draughtsman. Nils Walberg made clever mechanical modifications to the corer. Mikhail Kononets and Anders Tengberg helped with the turbidity measurements. The captains and crews of RVs 'Skagerak', 'Fyrbyggaren', 'Limanda' and 'KBV005' (including its diving team) assisted us ably. Financial support was provided by the Swedish Environmental Protection Agency (project 'A pilot study to evaluate effects of possible Baltic deep water Oxygenation', BOX) and the Foundation BalticSea2020 (project 'Permanent inactivation of phosphorus in Baltic sediments').

\section{LITERATURE CITED}

Ambühl H (1985) A technique for the preparation and presentation of sediment core samples with large cross section. Schweiz Z Hydrol 47:249-256 (in German with English summary)

Barnett PRO, Watson J, Connelly D (1984) A multiple corer for taking virtually undisturbed samples from shelf, bathyal and abyssal sediments. Oceanol Acta 7:399-408

Bett BJ, Vanreusel A, Vincx M, Soltwedel T and others (1994) Sampler bias in the quantitative study of deep-sea meiobenthos. Mar Ecol Prog Ser 104:197-203

Beukema JJ (1974) The efficiency of the Van Veen grab compared with the Reineck box sampler. J Cons Int Explor Mer 35:319-327

Billett DSM, Rice AL (2001) The BENGAL programme: introduction and overview. Prog Oceanogr 50:13-25

Black HJ, Dainat M, Köster M, Meyer-Reil LA (2002) A multiple corer for taking virtually undisturbed samples from shallow water sediments. Estuar Coast Shelf Sci 54: $45-50$

> Blomqvist S (1985) Reliability of core sampling of soft bottom sediment - an in situ study. Sedimentology 32:605-612

> Blomqvist S (1990) Sampling performance of Ekman grabs in situ observations and design improvements. Hydrobiologia 206:245-254

> Blomqvist S (1991) Quantitative sampling of soft-bottom sediments: problems and solutions. Mar Ecol Prog Ser 72 : 295-304

Blomqvist S, Abrahamsson B (1985) An improved Kajaktype gravity core sampler for soft bottom sediments. Schweiz Z Hydrol 47:81-84

Blomqvist S, Abrahamsson B (1987) A device for rapid sectioning of soft bottom sediment cores. Schweiz Z Hydrol 49:393-396

Blomqvist S, Boström K (1987) Improved sampling of soft bottom sediments by combined box and piston coring. Sedimentology 34:715-719

Boland GS, Rowe GT (1991) Deep-sea benthic sampling with the GOMEX box corer. Limnol Oceanogr 36: 1015-1020

Bouma AH, Marshall NF (1964) A method for obtaining and analysing undisturbed oceanic sediment samples. Mar Geol 2:81-99 
Burdige DJ (2007) Preservation of organic matter in marine sediments: controls, mechanisms, and an imbalance in sediment organic carbon budgets? Chem Rev 107: 467-485

Craib JS (1965) A sampler for taking short undisturbed marine cores. J Cons Int Explor Mer 30:34-39

DeMaster DJ (2002) The accumulation and cycling of biogenic silica in the Southern Ocean: revisiting the marine silica budget. Deep-Sea Res II 49:3155-3167

Ekeroth N, Lindström M, Blomqvist S, Hall POJ (2012) Recolonisation by macrobenthos mobilises organic phosphorus from reoxidised Baltic Sea sediments. Aquat Geochem 18:499-513

Ekman S (1911) Neue Apparate zur qualitativen und quantitativen Erforschung der Bodenfauna der Seen. Int Rev gesamten Hydrobiol Hydrogr 3:553-561

Ekman S (1933) Über einen neuen Bodengreifer für marinzoologische Zwecke, nebst Bemerkungen über die limnologische Bodengreifermethodik. Int Rev gesamten Hydrobiol Hydrogr 28:312-329

Elmgren R (1973) Methods of sampling sublittoral soft bottom meiofauna. Oikos (Suppl) 15:112-120

> Föllmi KB (1996) The phosphorus cycle, phosphogenesis and marine phosphate-rich deposits. Earth Sci Rev 40: $55-124$

Gage JD, Bett BJ (2005) Deep-sea benthic sampling. In: Eleftheriou A, McIntyre AD (eds) Methods for the study of marine benthos, 3rd edn. Blackwell Publishing, Oxford, p 273-325

Gage JD, Tyler P (1991) Deep-sea biology: a natural history of organisms at the deep-sea floor. Cambridge University Press, Cambridge

Gerber HW, Oebius HU, Grupe B (1996) MAXICORER. A device for taking undisturbed samples of sediment including the benthic boundary layer. Sea Technol 37: 66-69

Gerdes D (1990) Antarctic trials of the multi-box corer, a new device for benthos sampling. Polar Rec 26:35-38

Gruber N (2008) The marine nitrogen cycle: overview and challenges. In: Capone DG, Bronk DA, Mulholland MR, Carpenter EJ (eds) Nitrogen in the marine environment, 2nd edn. Elsevier, Amsterdam, p 1-50

Hayashi I, Sugino N (1993) Some observations on the sampling efficiency of the Smith-McIntyre grab. Bull Jpn Soc Sci Fish 59:1201-1207

> Hedges JI, Keil RG (1995) Sedimentary organic matter preservation: an assessment and speculative synthesis. Mar Chem 49:81-115

Hessler RR, Jumars PA (1974) Abyssal community analysis from replicate box cores in the central North Pacific. Deep-Sea Res 21:185-209

Howarth RW, Jensen HS, Marino R, Postma H (1995) Transport to and processing of $\mathrm{P}$ in near-shore and oceanic waters. In: Tiessen H (ed) Phosphorus in the global environment: transfers, cycles and management. John Wiley \& Sons, Chichester, p 323-345

Jahnke RA, Knight LH (1997) A gravity-driven hydraulically-damped multiple piston corer for sampling finegrained sediments. Deep-Sea Res I 44:713-718

Jamieson AJ, Boorman B, Jones DOB (2013) Deep-sea benthic sampling. In: Eleftheriou A (ed) Methods for the study of marine benthos, 4 th edn. John Wiley \& Sons, Chichester, p 285-347

Jensen P (1983) Meiofaunal abundance and vertical zonation in a sublittoral soft bottom, with a test of the Haps corer. Mar Biol 74:319-326

Jonasson A, Olausson E (1966) New devices for sediment sampling. Mar Geol 4:365-372

- Karl HA (1976) Box core liner system developed at the Sedimentology Research Laboratory, University of Southern California. Mar Geol 20:M1-M6

> Kornijów R (2013) A new sediment slicer for rapid sectioning of the uppermost sediment cores from marine and freshwater habitats. J Paleolimnol 49:301-304

> Laruelle GG, Roubeix V, Sferratore A, Brodherr B and others (2009) Anthropogenic perturbations of the silicon cycle at the global scale: key role of the land-ocean transition. Global Biogeochem Cycles 23, GB4031, doi:10.1029/ 2008GB003267

> Lund-Hansen LC, Christiansen C, Laima MJC (2001) A new video controlled, hydraulically damped corer for sediment/water interaction studies. Mar Georesour Geotechnol 19:147-154

McCave IN (1985) Sedimentology and stratigraphy of box cores from the HEBBLE site on the Nova Scotian continental rise. Mar Geol 66:59-89

- McIntyre AD (1971) Deficiency of gravity corers for sampling meiobenthos and sediments. Nature 231:260

Pamatmat MM (1971) Oxygen consumption by the seabed IV. Shipboard and laboratory experiments. Limnol Oceanogr 16:536-550

Papucci C, Jennings CD, Lavarello O (1986) A modified box corer and extruder for marine pollution studies. Cont Shelf Res 6:671-675

Paterson GLJ, Wilson GDF, Cosson N, Lamont PA (1998) Hessler and Jumars (1974) revisited: abyssal polychaete assemblages from the Atlantic and Pacific. Deep-Sea Res II 45:225-251

Peters RD, Timmins NT, Calvert SE, Morris RJ (1980) The IOS box corer: its design, development, operation and sampling. Rep 106. Institute of Oceanographic Sciences, Wormley

Probert PK (1984) A comparison of macrofaunal samples taken by box corer and anchor-box dredge. NZOI Rec 4 : 149-156

Rawson DS (1947) An automatic-closing Ekman dredge and other equipment for use in extremely deep water. Limnol Soc Am Spec Publ 18:1-8

Reineck HE (1958) Kastengreifer und Lotröhre 'Schnepfe', Geräte zur Entnahme ungestörter, orientierter Meersgrundproben. Senckenb Lethaea 39:45-48 and 54-56

Reineck HE (1963) Der Kastengreifer. Die Entwicklung eines Gerätes zur Entnahme ungestörter, orientierter Grundproben vom Meeresboden. Nat Mus 93:102-108

Rosfelder AM, Marshall NF (1967) Obtaining large, undisturbed, and orientated samples in deep water. In: Richards AF (ed) Marine geotechnique. University of Illinois Press, Urbana, IL. p 243-263

Ruttenberg KC (2004) The global phosphorus cycle. In: Schlesinger WH (ed) Biogeochemistry. Treatise on geochemistry, Vol 8. Elsevier Pergamon, Amsterdam, p 585-643

Sangiorgio F, Quintino V, Rosati I, Rodrigues AM, Pinna M, Basset A (2014) Macrofauna in Mediterranean and Black Sea transitional aquatic ecosystems: a comparative study of the benthic populations sampled by box corer and leaf bags. Ecol Indic 38:159-169

> Shirayama Y, Fukushima T (1995) Comparisons of deep-sea sediments and overlying water collected using multiple corer and box corer. J Oceanogr 51:75-82 
Smith KL Jr, Howard JD (1972) Comparison of a grab sampler and large volume corer. Limnol Oceanogr 17: 142-145

Somerfield PJ, Clarke KR (1997) A comparison of some methods commonly used for the collection of sublittoral sediments and their associated fauna. Mar Environ Res 43:145-156

Soutar A, Johnson S, Fischer K, Dymond J (1981) Sampling the sediment-water interface - evidence for an organicrich surface layer. Eos Trans AGU 62:905

Editorial responsibility: Myron Peck,

Hamburg, Germany
Veillette J, Sarrazin J, Gooday AJ, Galéron J and others (2007) Ferromanganese nodule fauna in the tropical North Pacific Ocean: species richness, faunal cover and spatial distribution. Deep-Sea Res I 54:1912-1935

Walsh JJ (1984) The role of ocean biota in accelerated ecological cycles: a temporal view. BioScience 34:499-507

Zettler ML, Pollehne F (2013) Namibian upwelling and its effects on macrozoobenthic diversity. In: Fischer WE, Green AB (eds) Upwelling. Nova Science Publishers, New York, NY, p 35-58

Submitted: July 30, 2014; Accepted: June 26, 2015

Proofs received from author(s): September 20, 2015 